\title{
Sistema Aquíleo Calcáneo Plantar
}

V. LEAL SERRA.

Hospital San Rafael de Barcelona.

\begin{abstract}
Resumen
El Sistema Aquíleo Calcáneo Plantar fue descrito por los Profesores Arandes y Viladot el año 1953 demostrando cómo el Tríceps sural que termina en el tendón de Aquiles, se refleja en la tuberosidad del calcáneo, continuando con la aponeurosis plantar y la musculatura corta plantar, hasta llegar a insertarse en los dedos del pie. Esto representó, desde el punto de vista biomecánico, un gran avance para la comprensión de la marcha, la carrera y el salto en el homo erectus.
\end{abstract}

Palabras clave: Pie, biomecánica, sistema aquíleo calcáneo plantar.

\begin{abstract}
The Achillean-calcaneous-plantar system was described by Professors Arandes and Viladot the year 1953 showing how the sural triceps that finishes in the Achilles' heel, reflects itself in the tuberosity of the heel bone, continuing with the plantar aponeurosis and the short plantar muscles, until insertion in the toes. This was, from a biomechanical point of view, a great advance for the understanding of the walk, the run and the jump in the homo erectus.
\end{abstract}

Keywords: toe, biomechanics, achillean-calcaneous-plantar system.

\section{Introducción}

El Sistema Aquíleo Calcáneo Plantar fue descrito por los Profesores Arandes y Viladot el año 1.953 demostrando cómo el Tríceps sural que termina en el tendón de Aquiles, se refleja en la tuberosidad del calcáneo, continuando con la aponeurosis plantar y la musculatura corta plantar, hasta llegar a insertarse en los dedos del pie. Esto representó, desde el punto de vista biomecánico, un gran avance para la comprensión de la marcha, la carrera y el salto en el homo erectus.

A continuación estudiaremos la Embriología, la Anatomía, la Cinemática, la Patología y la Filogenia del Sistema Aquíleo Calcáneo Plantar.

Correspondencia:

Víctor Leal Serra

Hospital San Rafael de Barcelona.

Psg. Vall d'Hebrón, 107-117.

08035 - Barcelona.

E-mail: vls6966@hotmail.com

\section{Embriología}

Se observa ya en el embrión de pocas semanas, en cortes sagitales, como existe una continuidad por detrás del calcáneo, del tendón de Aquiles con la aponeurosis plantar y con los músculos plantares (figura 1).

\section{Anatomía}

En un corte sagital del talón se ve claramente como el Tríceps sural termina en el tendón de Aquiles y éste adherido al sistema trabecular posterior e inferior del calcáneo se continúa con la aponeurosis plantar, el Abductor del dedo grueso, el Flexor corto del dedo grueso y el flexor corto plantar (figura 2).

\section{Cinemática}

En el vértice del talón existen dos líneas de fuerza, una vertical del tendón de Aquiles y otra horizontal de la aponeurosis plantar. El resultado de estos dos vectores coincide con el eje mayor de la tuberosidad del calcáneo (figura 3). 

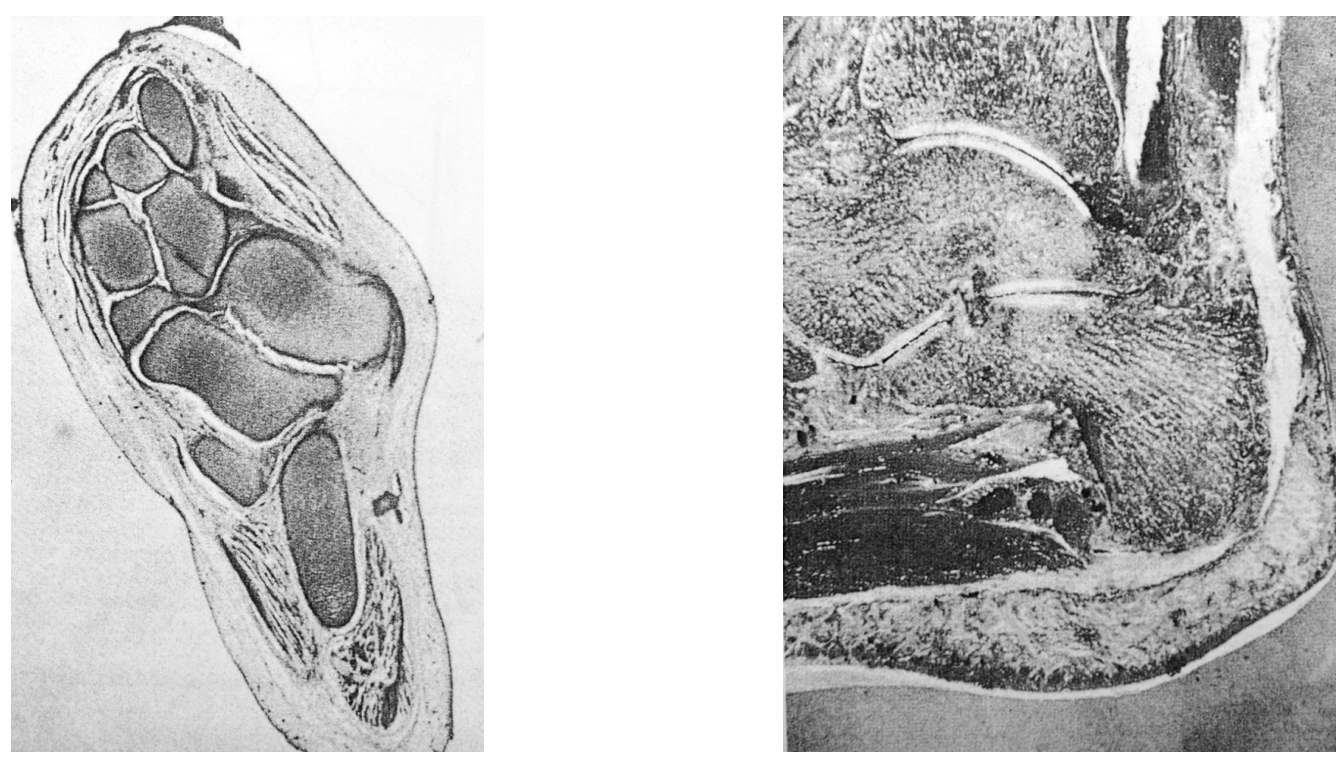

Figura 1 (izquierda). Sistema Aquíleo Calcáneo Plantar presente en el embrión.

Figura 2 (derecha). El tendón de Aquiles se continúa con la aponeurosis y la musculatura corta plantar.

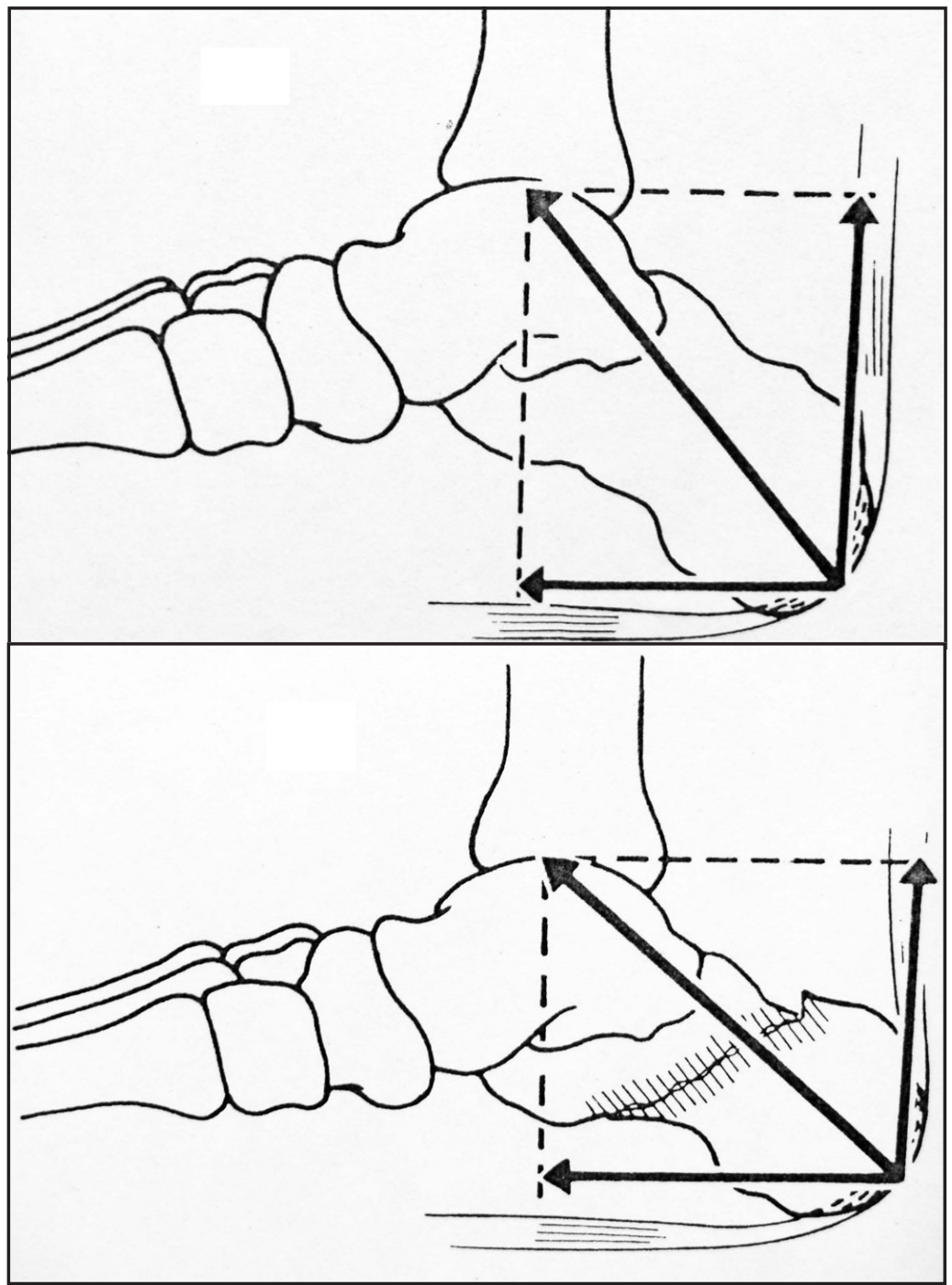

Figura 3 (arriba). La resultante de los dos vectores coincide con el eje de la tuberosidad mayor del calcáneo. Figura 4 (abajo). Disminución de la longitud de la tuberosidad. 


\section{Patología}

Todo este sistema que de forma magistral dinamiza la marcha, puede verse seriamente alterado en diversas patologías como son las fracturas del calcáneo, el pie talo, el pie espástico, el pie zambo, las epifisitis plantares y los espolones calcáneos. Estudiaremos por separado cada una de ellas.

Fracturas del calcáneo. En las fracturas de calcáneo con hundimiento talámico, los vectores se acortan y el resultado es que hay una disminución de la longitud de la tuberosidad (figura 4) con la consiguiente pérdida de fuerza de todo el sistema. De aquí la gran importancia que tiene la correcta reducción y estabilización de estas fracturas que son siempre graves, ya que el calcáneo es un hueso corto y muy esponjoso, por lo que al reducir el hundimiento queda siempre un hueco que co- rresponde a la esponjosa aplastada y no es fácil de rellenar y estabilizar.

Pie talo. Se produce por una parálisis del Tríceps sural que deja el vector vertical correspondiente al tendón de Aquiles totalmente inerte, produciendo una grave deformidad del pie por el gran predominio del Tibial anterior y el Extensor común de los dedos que fuerzan el pie hacia arriba y la aponeurosis plantar sin oposición, rompe el equilibrio del sistema acortando la planta del pie. Si esta situación se produce durante el periodo de crecimiento, la aponeurosis plantar insertada en el núcleo epifisario, al romperse el equilibrio con el tendón de Aquiles, fuerza el desplazamiento anterior del núcleo epifisario del calcáneo (figura 5) con el consiguiente desarrollo anormal de este hueso, aumentando todavía más la deformidad del pie si no se le pone remedio con anterioridad (figura 6).

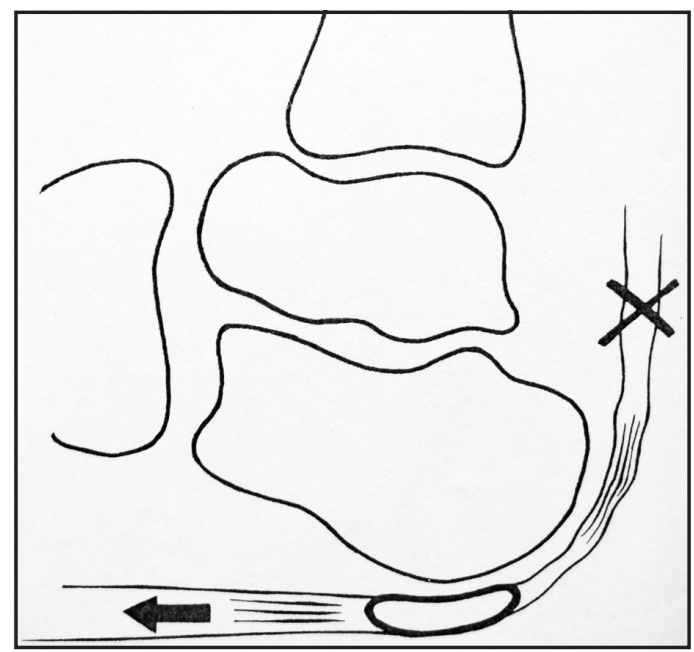

Figura 5. Desplazamiento anterior del núcleo epifisario del calcáneo.

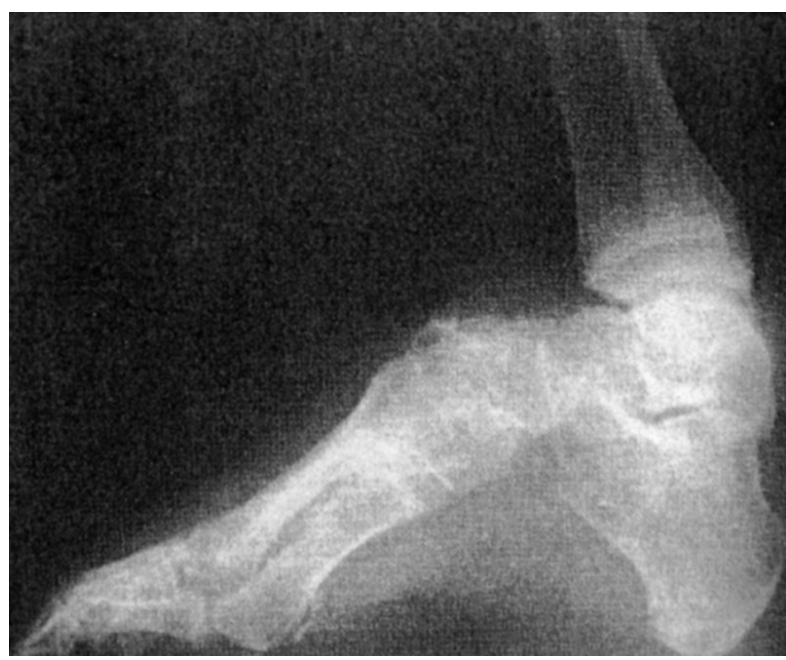

Figura 6. Deformidad por parálisis del tríceps sural. 
Pie espástico. Existe un gran predominio de la fuerza del vector vertical correspondiente al tendón de Aquiles por retracción del tríceps sural (figura 7). El talón asciende y el pie se verticaliza en una exagerada flexión plantar. Si la musculatura plantar es potente se forma un pie equino directo (figura 8) en el que el apoyo se produce directamente sobre los dedos del pie, sin que exista el apoyo plantar. Si por el contrario, la musculatura plantar cede, se produce un pie plano convexo en el que astrágalo y calcáneo están verticalizados y el apoyo plantar se produce por una gran hiperextensión de la articulación de Chopart (figura 9).

Pie zambo. En el pie zambo equinovaro congénito, existe un equinismo del pie acompañado por un varo del talón y una supinación del antepié. Es como si todo el Sistema Aquíleo Calcáneo Plantar estuviese desplazado hacia la parte interna del pie arrastrando consigo el núcleo epifisario del talón (figura 10), con la consiguiente agravación de la deformidad durante el desarrollo si no se le pone remedio lo más precozmente posible (figura 11). Un pie zambo no tratado puede llegar a la maduración ósea con un grado de deformidad tan importante que a la deambulación, el apoyo se produzca por el dorso del pie y no por la planta.

Ponsetti preconiza el tratamiento desde el nacimiento, mediante yesos correctores y el uso posterior de férulas de mantenimiento durante varios años. Con este método ha publicado brillantes resultados sin necesidad de recurrir al tratamiento quirúrgico. En la actualidad ha sido mundialmente reconocido, pero hay que recalcar que no es un procedimiento fácil y que requiere un largo perio-

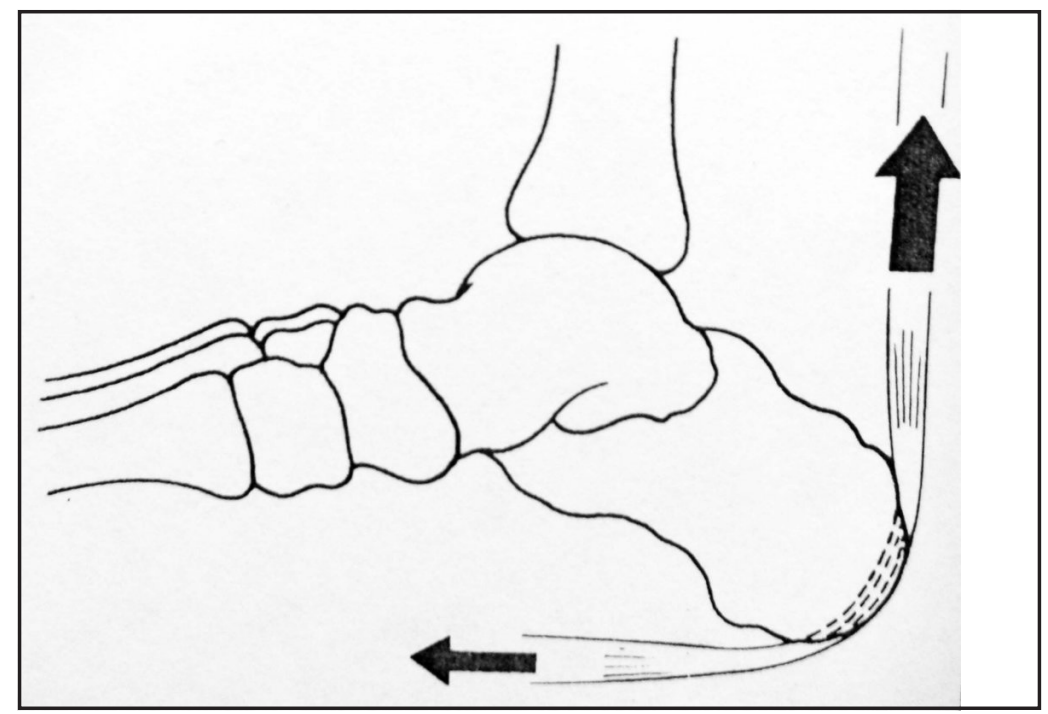

Figura 7. Aumento de la fuerza del vector Aquíleo.

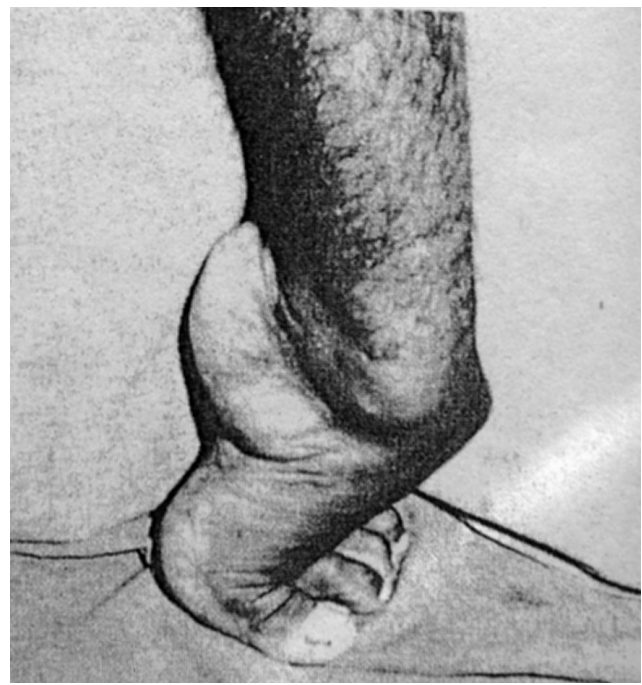

Figura 8. Pie equino directo.

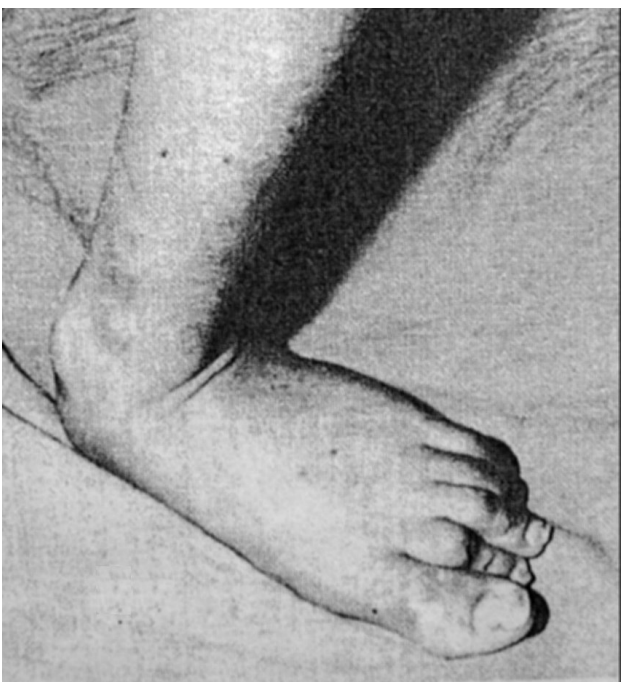

Figura 9. Pie plano convexo. 
do de aprendizaje para conseguir las correcciones manuales necesarias y la posterior colocación de los yesos, sin incurrir en maniobras intempestivas que podrían agravar más si cabe, la deformidad de estos huesos en crecimiento.

Otras escuelas abogan por el tratamiento inicial con vendajes elásticos, no vendajes rígidos, empezando por la corrección del varo del talón, seguida de la supinación del antepie y finalmente, cuando el pie es un poco más elástico, se corrige el equinismo. Posteriormente, se colocan férulas de mantenimiento de la corrección durante unos años, controlando su evolución. Si la corrección de la deformidad no se consigue en el plazo de unos ocho a doce meses, se recurre al tratamiento quirúrgico, mediante la intervención de Codivilla con artrotomía del arco interno, teniendo especial cuidado de evitar las recidivas mediante un control exhaustivo y sobre todo las hipercorrecciones, por excesivo alargamiento tendinoso o por lesión del ligamento Deltoideo que dejará como secuela un pie plano valgo importante.

Epifisitis. Descrita por Haglund en 1902, como una malformación del calcáneo y por Sever en 1912 como una condromalacia de la epífisis de crecimiento del talón.

La mal llamada "Enfermedad de Haglund" es una deformidad del calcáneo en forma de exóstosis en la parte posterior que le da el aspecto de un calcáneo alto y abollado que al rozar con el contrafuerte del zapato, presiona el tendón de Aquiles contra el hueso y puede dar lugar a una bursitis preaquílea que dificulta en gran manera la deambulación (figura 12). Su tratamiento consiste en rebajar la inflamación, utilizar calzado blando que no roce con el contrafuerte, sobre todo en verano llevar un calzado destapado por detrás, con el fin de curar la bursitis. En los casos crónicos, en los que fracasa cualquier intento conservador, la cirugía consiste en rebajar totalmente la exóstosis normalizando la forma anatómica del calcáneo.
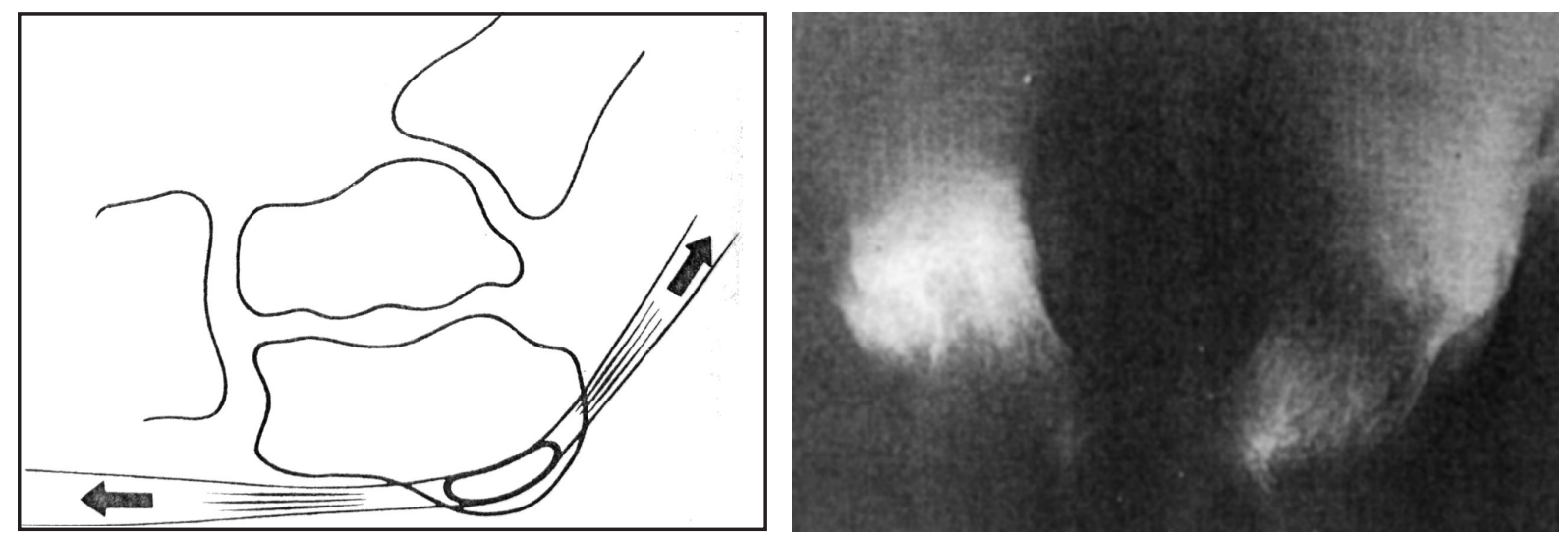

Figura 10 (izquierda). Desplazamiento interno del núcleo epifisario del calcáneo.

Figura 11 (derecha). Deformidad en varo del calcáneo.

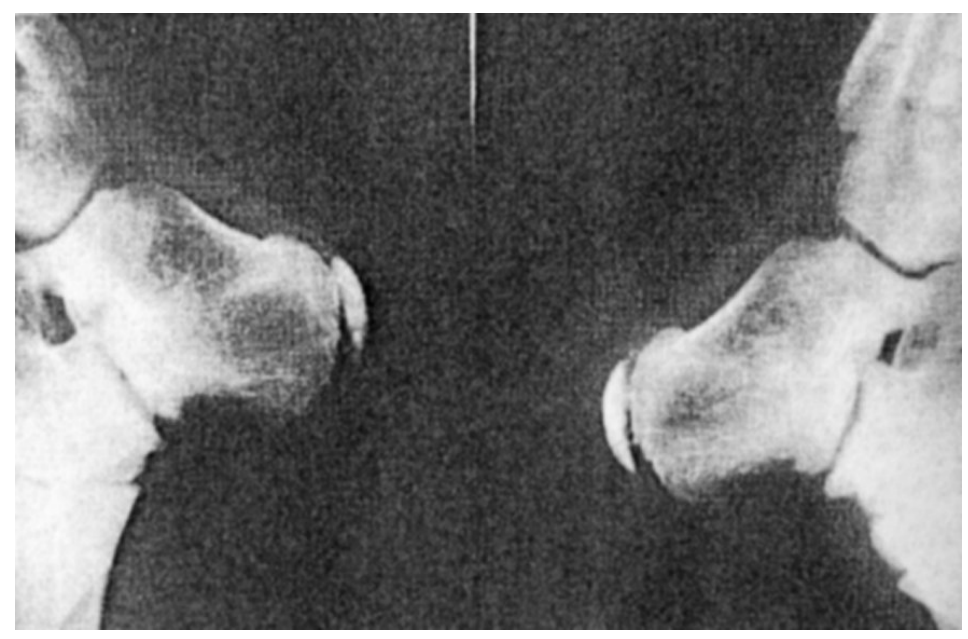

Figura 12. Epifisitis posterior del calcáneo. 
La verdadera epifisitis posterior del calcáneo, es la enfermedad de Sever. El núcleo de crecimiento en el talón aparece entre los seis y los ocho años de edad y osifica hacia los dieciséis a dieciocho años (figura 13). Durante todo el periodo de crecimiento el tendón de Aquiles se continúa con la aponeurosis plantar a través de este núcleo de crecimiento a modo de rotula, así en determinadas ocasiones, en niños que practican mucho deporte sobre todo carrera y salto, o después de una excursión larga, aparece un dolor en el talón que incluso puede obligar al niño a caminar apoyando solo el antepie. Se trata siempre de un dolor temporal que puede durar algún tiempo y remite siempre con antiinflamatorios, reposo relativo y solo en determinadas ocasiones, plantillas para descarga del talón.

Espolones. Se trata de una osificación localizada en la cara plantar o posterior del calcáneo, por lo que distinguimos entre espolones plantares y posteriores, aunque pueden estar asociados (figura 13). Su mecanismo de producción es por una tracción excesiva o microtraumatismos repetidos en los puntos de inserción del tendón de Aquiles y la aponeurosis plantar, lo que produce una inflamación cuya hiperemia es causa de decalcificación del hueso. Al remitir la hiperemia el calcio se deposita en el tejido de granulación producido por la reacción inflamatoria, formándose de esta manera el espolón. No se trata pues de una enfermedad, sino de una alteración pasajera del sistema Aquíleo Calcáneo Plantar, ya que el espolón duele mientras se está formando, pero en teoría, una vez ha osificado deja de doler. El problema es que este proceso puede ser largo, pero debe seguirse un tratamiento conservador a ultranza, mediante reposo, antiinflamatorios, plantillas para descarga del ta- lón y si es preciso infiltraciones que deben realizarse por vía lateral o directamente sobre el nervio tibial posterior por detrás del maleolo interno. El tratamiento quirúrgico es siempre excepcional.

Filogenia. El Dr. Josep Domingo Pech et al. realizaron un interesante trabajo sobre la evolución del Sistema Aquíleo Calcáneo Plantar, disecando la pata posterior de una rana, una tortuga, un cocodrilo y un perro con los siguientes hallazgos y conclusiones:

Se escogió la rana como primer eslabón ya que es una de las formas más primitivas de la vida terrestre. En la radiografía (figura 14) se ve que la rana no tiene talón y que el astrágalo y el calcáneo son dos huesos largos como los metatarsianos. Cuando disecamos el sistema flexor de los dedos (figura 15), aislamos un músculo homólogo al tríceps sural que se continúa por una rotula posterior y termina con la aponeurosis plantar, en la última falange de los dedos. Estas estructuras, son el homólogo del sistema Aquíleo Calcáneo Plantar del hombre. Es decir, anatómicamente, la rana no tiene un sistema Aquíleo Calcáneo Plantar, pero tampoco lo necesita ya que la rana no camina, sino que nada y salta, cosa que se ve facilitada en gran manera por la existencia de este músculo, semejante al tríceps, que termina en la última falange de los dedos.

La tortuga. En el Mesozoico, con la aparición de los grandes reptiles, la masa de un cuerpo pesado sobre el arco que constituye la pata posterior tiende a condensar en un bloque compacto los dos huesos largos que constituyen el astrágalo y el calcáneo de los anfibios, así en la tortuga estos dos huesos se unen y forman una masa cúbica (figura 16). La tortuga utiliza sus patas como pilones desde la rodilla al pie y su cuerpo pende

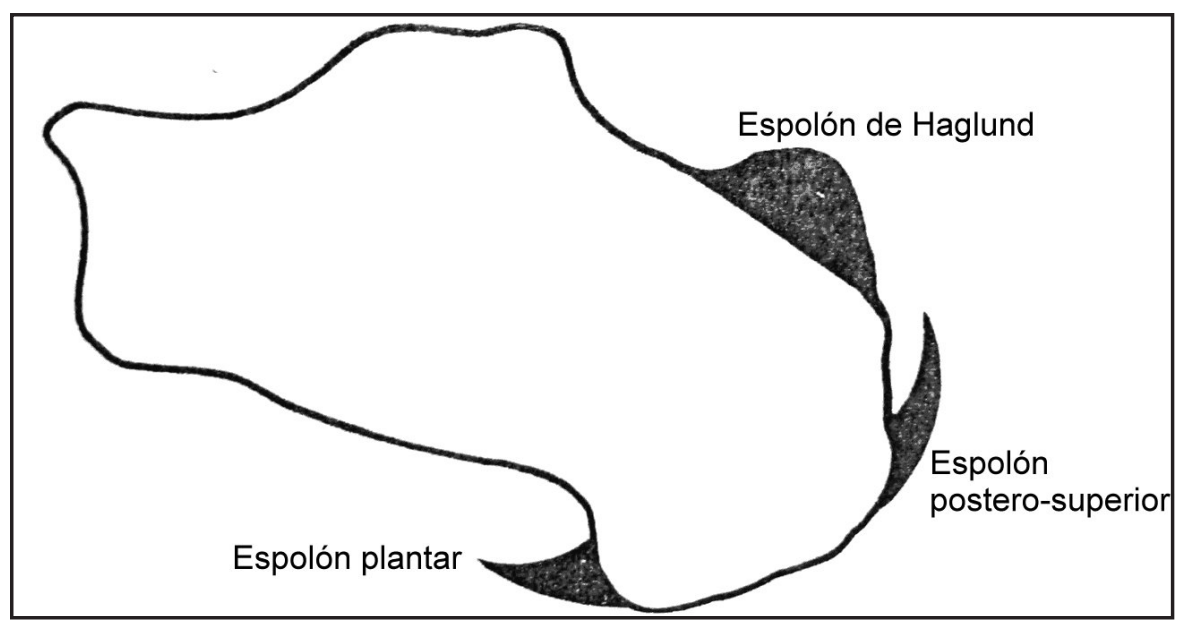

Figura 13. Exóstosis de Haglund. Espolones calcáneos plantares y posteriores. 

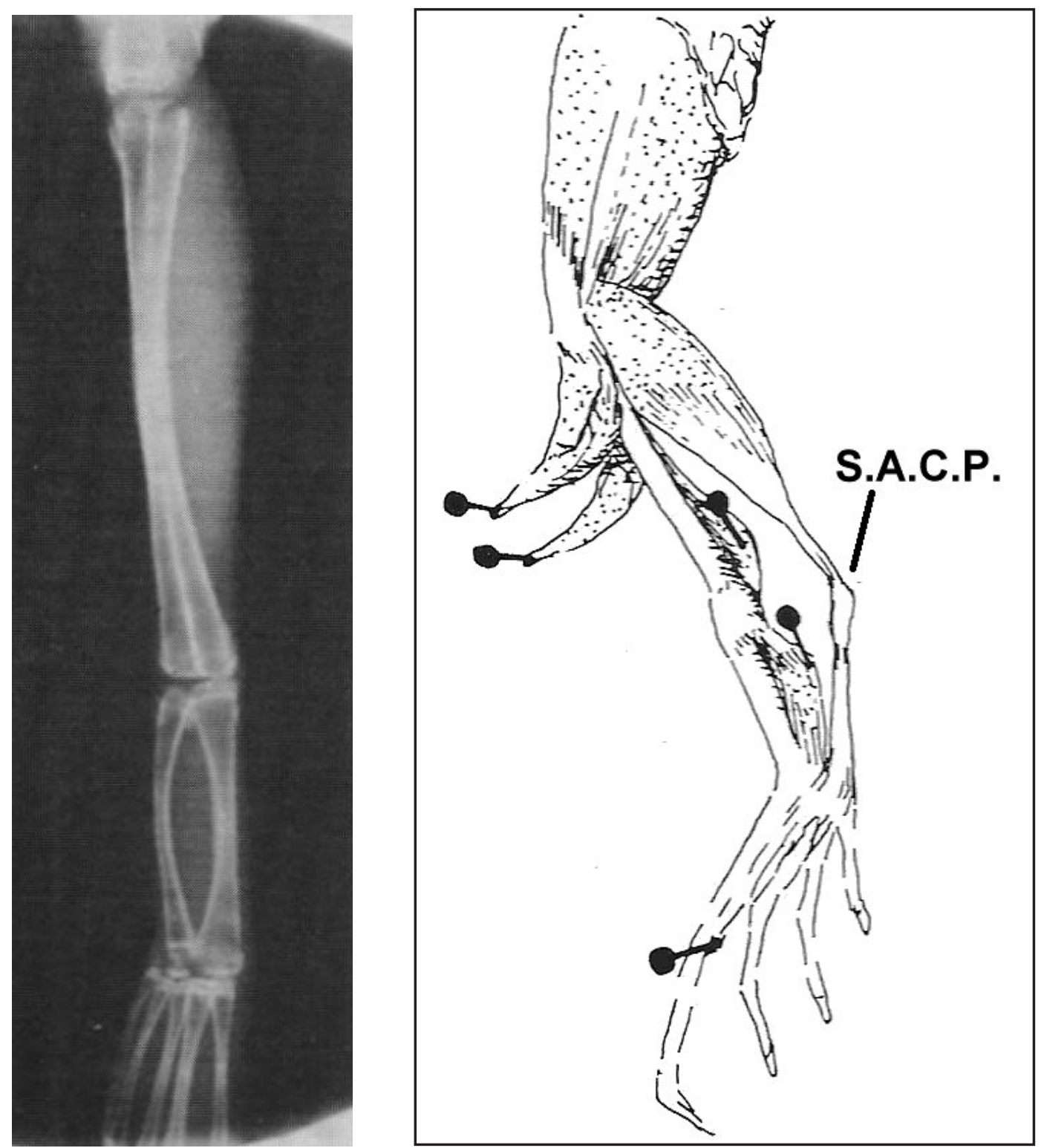

Figura 14 (izquierda). Radiografía de la pata de la rana.

Figura 15 (derecha). Músculo homólogo al tríceps sural en los dedos de rana.

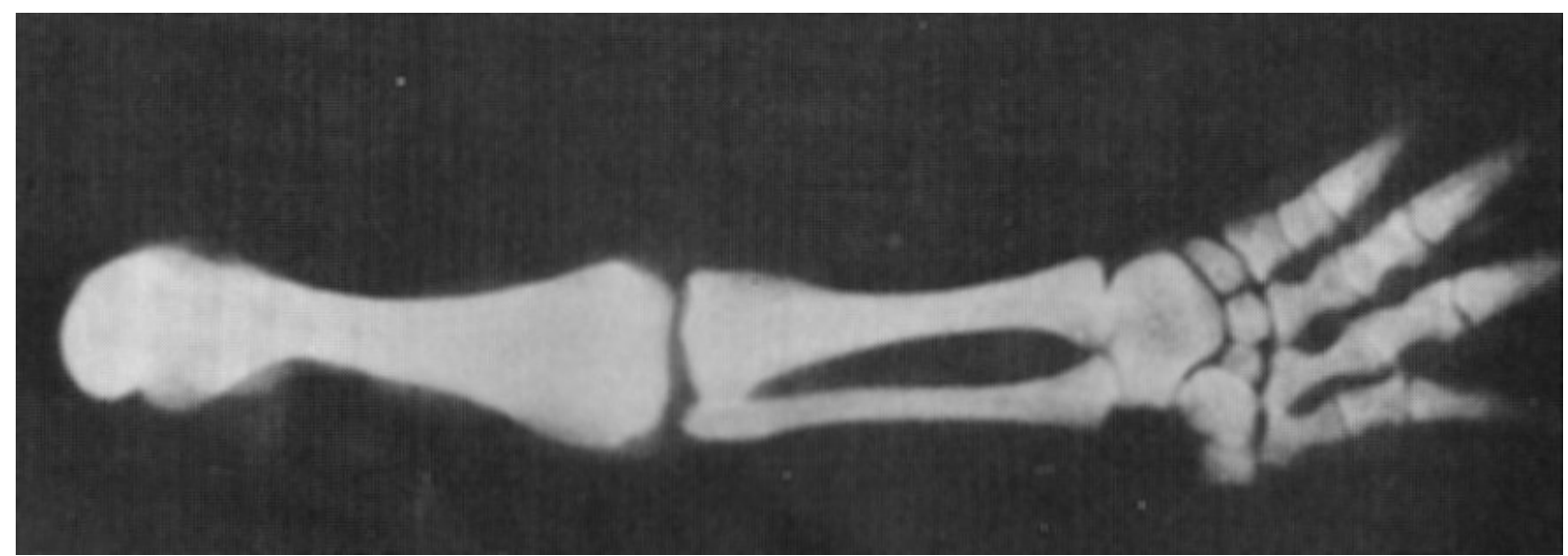

Figura 16. Radiografía de la pata de la tortuga. 
entre sus miembros como una hamaca, por lo que su marcha es lenta y laboriosa. En la musculatura de la pata de la tortuga no se encuentran elementos diferenciados semejantes al sistema Aquíleo Calcáneo Plantar (figura 17) aunque llama la atención la longitud del homólogo del tendón de Aquiles humano. Así pues la tortuga tampoco tiene un sistema Aquíleo Calcáneo Plantar que le ayude a aumentar su velocidad, pero tampoco lo necesita ya que la tortuga no caza y cuando es atacada no corre porque su enorme caparazón es suficiente protección para encogerse y meterse dentro.

Las extremidades de los reptiles "modernos" como el cocodrilo, tienen los codos orientados ha-

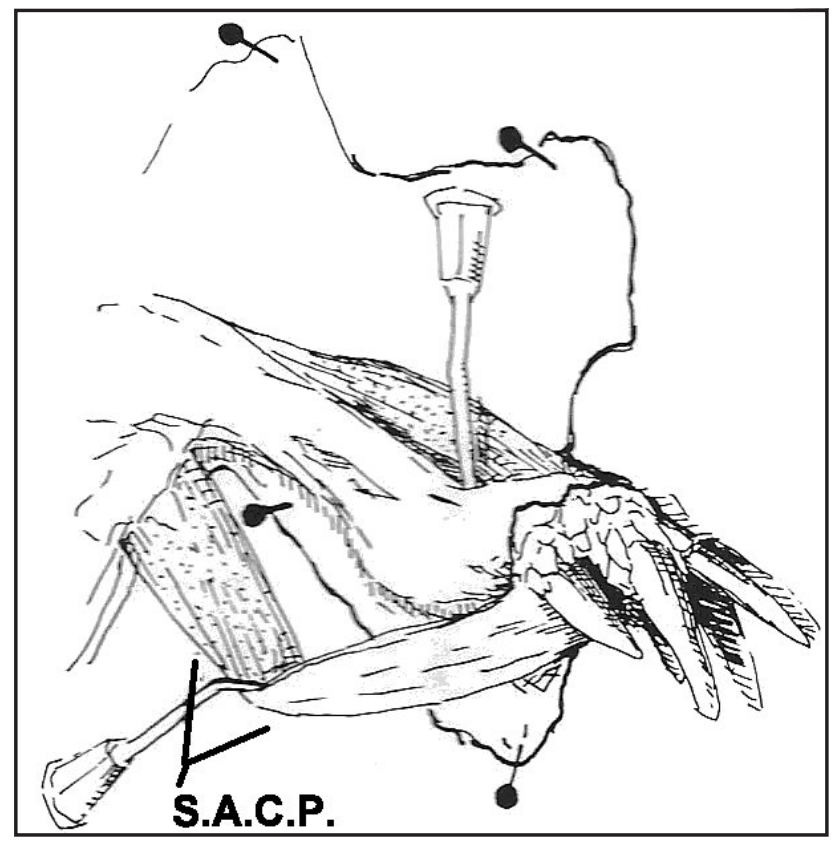

Figura 17. Homólogo al tendón de Aquiles en la pata de tortuga.
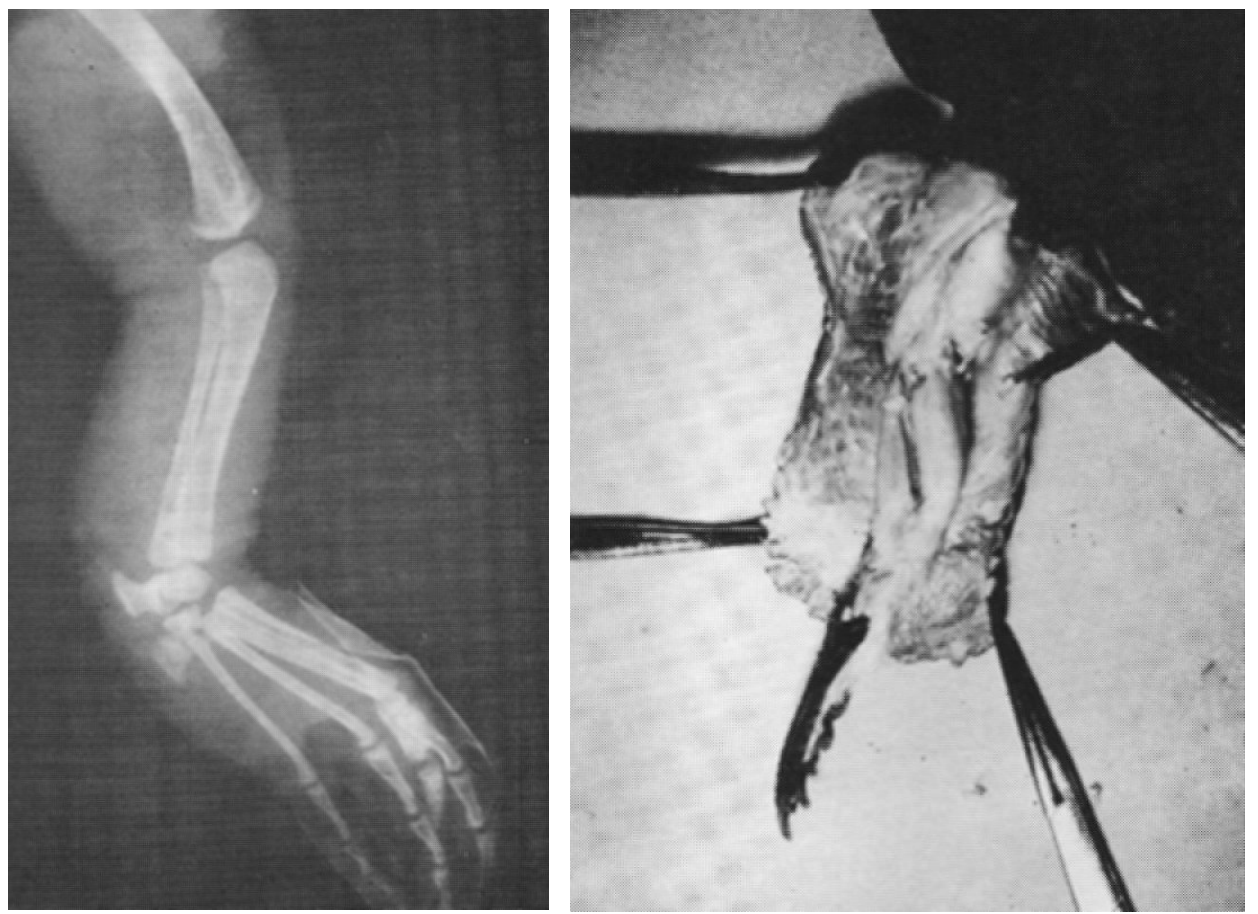

Figura 18 (izquierda). Radiografía de la pata del cocodrilo.

Figura 19 (derecha). Tríceps sural del cocodrilo. 
cia atrás y las rodillas hacia adelante. La marcha es así más armoniosa y regular. En las radiografías (figura 18) se puede observar el desarrollo de la tuberosidad posterior del calcáneo que aumenta el brazo de palanca del tríceps sural. La disección de la extremidad posterior del cocodrilo (figura 19) nos muestra como el tríceps sural se desliza por detrás del talón hacia las últimas falanges de los dedos. Por primera vez en la escala filogenética aparece un sistema Aquíleo Calcáneo Plantar que contribuye a aumentar la fuerza ejercida sobre los dedos permitiendo una mejor tracción y una marcha más rápida.

Se tomó como ejemplo de mamíferos cuadrúpedos el perro. Los cuadrúpedos precisan de la velocidad para perseguir a sus presas o para huir de sus perseguidores, para ello disponen de un aumento de la fuerza de tracción de sus patas posteriores, gracias al aumento del brazo de palanca posterior por el desarrollo definitivo de la tuberosidad posterior del calcáneo. En la figura 20 se aprecia claramente como los gastrocnemios se insertan en el talón, mientras que el sóleo se desliza por un ojal muscular, contornea la tuberosidad posterior del calcáneo del que está separado por una bolsa serosa y termina insertándose en la última falange de los dedos.

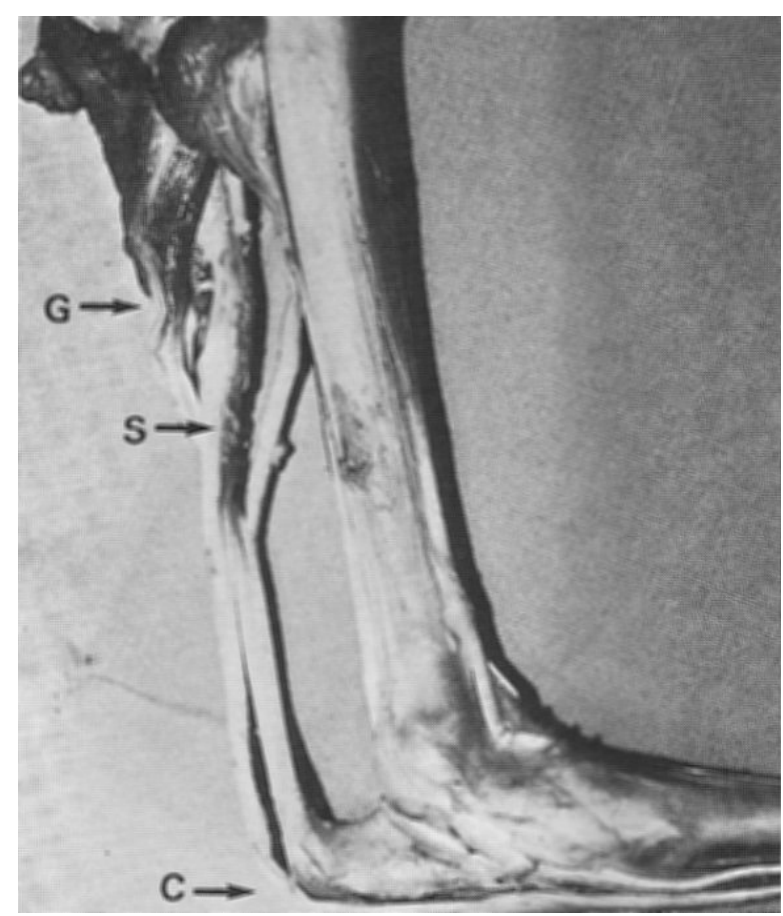

Figura 20. Sistema Aquíleo Calcáneo Plantar en el perro.

\section{Conclusión}

Al observar las estructuras que llegarán a formar el sistema Aquíleo Calcáneo Plantar, se aprecia que lo esencial es el crecimiento lento del brazo de palanca posterior y por consiguiente de la fuerza de tracción de los dedos permitiendo mejorar la velocidad. Hasta aquí la primera fase de la formación del sistema Aquíleo Calcáneo Plantar. En la fase siguiente, el calcáneo cae contra el suelo y el sistema se adapta a una nueva situación que es la bipedestación humana. La evolución hacia la velocidad se terminó y la cerebración debe imponerse.

Valga la transcripción de estos magníficos trabajos como homenaje a mis maestros en ortopedia y traumatología respectivamente. 